\title{
New Composite Construction Material for Low Cost Underground Water Tanks
}

\author{
S. M. A. Nanayakkara and V. A. S. P. Nanayakkara
}

\begin{abstract}
There is a great need for developing designs and construction technologies for low cost water tanks, specially for rain water harvesting. This research was carried out to introduce such tanks with the use of low cost materials like brickwork and ferro-cement.
\end{abstract}

A computer program was developed to analyze cylindrical tanks with spherical shell bottom and roof under various boundary conditions based on membrane and bending theory of shells. The computer program is capable of analyzing tanks with flat bottom as well as inverted spherical dome. Both fully underground and partially underground tanks can be analyzed using this program.

A parametric study was carried out by using the computer program. The results revealed that the maximum capacity that can be achieved by using brickwork for the spherical roof and the cylindrical wall of the tanks is only about $10 \mathrm{~m} 3$. The governing factor in deciding the capacity is the flexural strength of brickwork. Hence, brickwork reinforced with wire mesh was considered for the cylindrical wall. Extensive experimental investigations were carried out to obtain material properties of brick work, ferro-cement and the reinforced brickwork with wire mesh. The experimental investigations revealed that the flexural strength could be increased considerably with this new composite construction material named "Brickwork Reinforced with Wire Mesh (BRWM".

According to the results of the parametric study, maximum tank diameter that can be achieved for a partially underground tank having a ferro-cement spherical roof, BRWM cylindrical wall and a ferrocement inverted spherical bottom is about $6 \mathrm{~m}$ which resulted in an approximate capacity of $100 \mathrm{~m}^{3}$.

\section{Introduction}

Various types of underground water tanks are used in many parts of the world to store water for domestic, irrigation and industrial purposes. There is a great need to construct the said tanks in Sri Lanka also, especially in the dry zone, for the purpose of ensuring water security by enabling practices such as rainwater harvesting.

The National Water Supply and Drainage board (NWSDB) has already been involved in the construction of low cost ground level tanks using ferro-cement. The capacity of these cylindrical tanks with domed roofs has been gradually increased up to $30 \mathrm{~m}^{3}$ (Herath, 1995). A study carried out at the University of Paradeniya has resulted in a proposal for an 80 $\mathrm{m}^{3}$ ground level cylindrical tank with a central roof support (Kumara et al 1999).

The NWSDB has also expressed the need to explore the avenues of having low cost underground water tanks with large capacities using brickwork as a suitable construction material. Hence, the research project was commenced.

\section{Objectives and scope of the study}

The main objective of the study is to carry out structural analysis and design of the underground water tanks with low cost construction materials such as brickwork and ferro-cement. A secondary objective of the study is to investigate the maximum capacities that can be achieved by using different construction materials for different parts of the tank (i.e. for roof, wall and bottom) considering fully underground as well as partially underground tanks.

Eng. (Dr.) S.M.A. Nanayakkara - B.St: Eng. M.Eng. D.Eng. C.Eng. MIE(SL, Presently Senior Lecturer,Department of Civil Enginerring. Universiby of Moratuw'a

Ms. VA.S.P. Nanajaktkare - B.Sc.Eng. M.Sc., Presently; Graduate student. Universily of Calgany 
The scope of the study is limited to the cylindrical tanks with flat and inverted spherical bottoms. As construction materials, mainly brickwork and ferro-cement were considered as their costs are fairly low compared to concrete. Furthermore, a new composite construction material "Brick work reinforced with wire mesh" which combines the merits of both brickwork and ferro-cement was also considered.

\section{Structural analysis of the tanks}

A literature survey was carried out in order to determine the state of the art with respect to various types of tanks, which had been constructed in Sri Lanka as well as in other countries (Rees Dai 2000, Thomas 1997, Vadhanavikkit 1983). With the knowledge gained from the literature survey, two tank shapes (i.e. Flat bottom and Spherical bottom) were selected (see Fig. 1). The main reasons for the selection are to utilize the confinement due to earth pressure and the structural advantage of double curvature thin shells.

For the purpose of analysis, the tanks are represented by a system of simple members (spherical shells, cylindrical shells, circular plates and ring beams) that mechanically interact with each other. Edge restraining forces at the junction of different members were determined by solving compatibility equations for deformations at the junctions (Ranjendram 1965). The compatibility equations consist of deformations at the boundaries due to the primary loadings (self weight and imposed loads) and edge restraining forces. The deformations due to the primary loadings and edge restraining forces were obtained based on membrane and bending theory of thin shells respectively (Baker 1972).

A customized computer program was developed by incorporating the analytical solutions based on linear elastic theory of shells as structural analysis of the tanks by manual methods would be a very tedious and timeconsuming task.

\section{Structural design of tanks}

The design method adopted is based on the principle that all structural members should have design strength (maximum allowable stress) at all sections, at least equal to the design stress for the factored load and load combinations. The factored load and load combinations were considered for both ultimate and serviceability limit states. Experimental investigation was carried out to determine the strength properties of the construction materials considered in this study.

The design strength (i.e. the maximum allowable stress) is determined by dividing the failure stress by a partial safety factor appropriate for the material. The failure stress is taken as the stress corresponding to the first visible crack, as it is critically important in designing a liquid retaining structure to ensure that the structure is able to retain liquid without leakage, throughout its service life.

\section{Experimental investigation}

Experimental investigation was carried out to find the mechanical properties of brickwork, brickwork reinforced with wire mesh and ferrocement.

\subsection{Mechanical properties of brickwork}

In Sri Lanka, structural design in brickwork is carried out in accordance with BS 5628 : Part 1: 1992. However, the values of the properties given in the BS 5628 code are not relevant to Sri Lankan conditions as the quality of locally available bricks is not up to the required standard. Therefore, several tests were performed to investigate the following properties of brickwork.

- Compressive strength of brick units

- Compressive strength, modulus of elasticity and Poisson's ratio of brickwork

- Flexural strength of brickwork and brickwork reinforced with wire mesh

All bricks used for the determination of properties of brickwork were hand made bricks. A sample of ten bricks was selected from these bricks and tested in accordance with the guidelines given in SLS 39: 1978 for the determination of compressive strength of bricks. According to the test results the average compressive strength of bricks is $4.74 \mathrm{MPa}$. Therefore, bricks can be classified as grade 2 of type 2 bricks. 


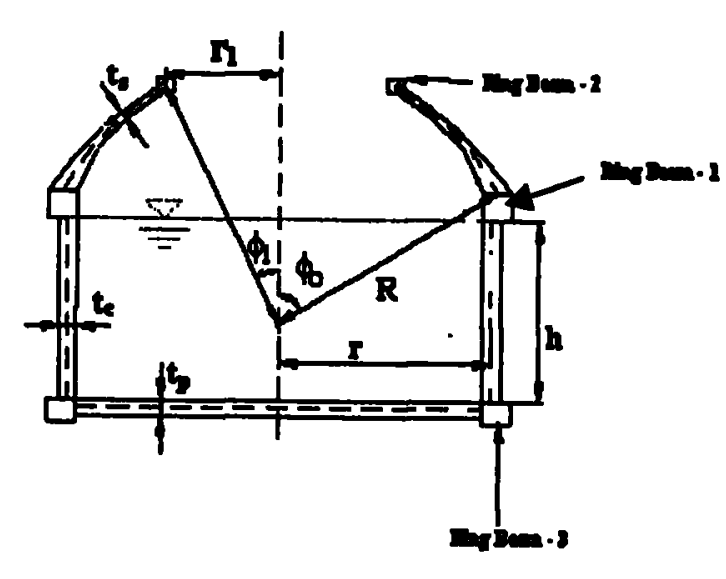

"Type 1" tank

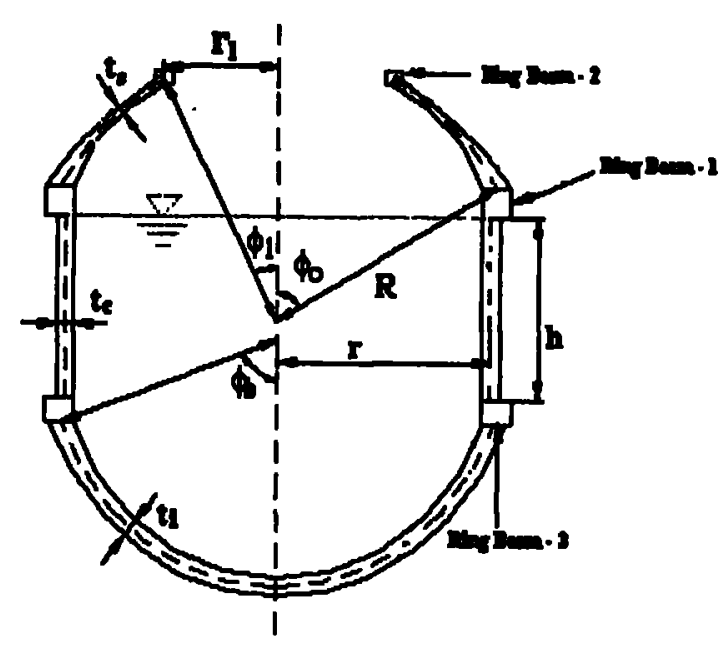

"Type 2" tank

Fig. 1 Geometry of tank shapes

Table 1: Compressive strength, Young's modulus and Poisson's ratio of brickwork

\begin{tabular}{|c|c|c|}
\hline $\begin{array}{c}\text { Compressive } \\
\text { strength, } \mathbf{N} / \mathrm{mm}^{2}\end{array}$ & $\begin{array}{c}\text { Young's Modulus, } \\
\mathrm{KN} / \mathrm{mm}^{2}\end{array}$ & $\begin{array}{c}\text { Poisson's } \\
\text { ratio }\end{array}$ \\
\hline 1.18 & 0.35 & 0.13 \\
\hline
\end{tabular}

5.1.1 Young's modulus, Poisson's ratio and compressive strength of brickwork

Four brick columns of $225 \mathrm{~mm} \times 225 \mathrm{~mm}$ were tested to determine the Young's modulus, Poisson's ratio and compressive strength of brickwork. Each column consists of four brick courses constructed with 1: 3 cement sand mortar. The test results are given in Table 1.

\subsubsection{Flexural strength of brickwork and brickwork reinforced with wire mesh}

Flexural strength of brickwork for perpendicular to bed joint and parallel to bed joint is not the same, as the material is not isotropic. Several brick panels were tested to investigate the effect of the following parameters on the flexural strength;

- Reinforcing wire mesh

- Mortar mix used to construct brick panels

- Construction method used to attach the reinforcing wire mesh

Twenty-eight brick panels were tested by varying the above parameters and the summary of the results are given in Table 2 . The tests were carried out according to the guidelines given in BS 5628: Part 1:1992.
CM1: Wire mesh was fixed on to the plastered brick panel and another $10 \mathrm{~mm}$ thick layer of plaster was applied to cover the mesh. The mesh was fixed by using $U$ shaped staples at $150 \mathrm{~mm}$ centres.

CM2: Wire mesh was directly fixed to the brick work and $10 \mathrm{~mm}$ thick mortar layer was applied to cover the mesh.

Following observations can be made based on the test results.

i. Flexural strength parallel to bed and perpendicular to bed had improved considerably by having a mesh on the tension face.

ii. No significant effect on the flexural strength was observed by having mesh on both tension and compression faces of the brick panel.

iii. Flexural strength for both directions (i.e. parallel to bed and perpendicular to bed) is high when adopting construction method 2 (CM2). Therefore, it was decided to adopt method CM2 for the construction of brick walls of the tanks.

iv. For brickwork without mesh, flexural strength in the perpendicular to bed direction is approximately nine times higher than the flexural strength in the parallel to bed direction. However, when No. 4 or No. 6 mesh was used, the difference between the flexural strength for 
the two directions (i.e. parallel to bed and perpendicular to bed) was not significant. This implies that when No. 4 or No. 6 mesh is used, the flexural strength is mainly governed by the strength of the mesh rather than the brickwork.

v. There was no considerable difference between the flexural strengths obtained by using mesh No. 4 and mesh No 6. Since the cost of mesh No. 6 is considerably higher than that of mesh No. 4, it was decided to use mesh No. 4.

Based on the above mentioned observations, flexural strength values corresponding to brickwork belonging to BT 1, BT 2 and BT 5 were used with the relevant safety factors for the parametric study and for structural design of the tank.

\subsection{Mechanical properties of Ferro-cement}

Ferro-cement is a form of reinforced concrete using closely spaced multiple layers of mesh and/or small diameter rods completely infiltrated with, or encapsulated, in mortar (ACI 549.1R, 1993). Numerous theoretical and experimental studies have been undertaken all over the world regarding various aspects of ferro cement and many articles have been published (Herath 1995, Kumar 1992, Kumara 1999). Since the results of those researches are not directly applicable to the type of ferrocement that is intended for use in this project, tests have been carried out to investigate the properties of ferro-cement using local materials.

\subsubsection{Flexural strength of ferro-cement}

The flexural strength of ferro-cement is the same for the two orthogonal directions as the distribution of reinforcement is uniform throughout the material. The dimensions of the specimens for flexural strength test were selected according to the guidelines given in ACI 549.1R -93.

Mild steel bars $(6 \mathrm{~mm}$ dia.) at $150 \mathrm{~mm}$ spacing were used as transverse and longitudinal skeletal steel and No.4 GI woven mesh on both sides of the R6 skeletal steel was used as reinforcement of $40 \mathrm{~mm}$ thick ferro-cement specimens.

The cement mortar $1: 3$ (by volume) with $w / c$ of 0.5 was used in making ferro-cement. Since the sieve size normally available in construction sites is $1.8 \mathrm{~mm}$ square mesh, sand sieved by 1.8 $\mathrm{mm}$ sieve was used in the mix. The flexural strength of the ferro-cement obtained from the test series is $1.0 \mathrm{~N} / \mathrm{mm}^{2}$.

\subsubsection{Compressive strength of mortar}

Compressive strength of mortar is used to assess the ultimate compressive strength of ferrocement. The ultimate compressive strength of ferro-cement is lower than that of equivalent pure mortar (Paul \& Pama, 1978). Therefore the compressive strength at ultimate conditions of ferro-cement is obtained by dividing the compressive strength of mortar by a partial safety factor.

Six test cubes, each having $70.1 \mathrm{~mm} \times 70.1 \mathrm{~mm} \times$ $70.1 \mathrm{~mm}$ dimensions, were cast using $1: 3$ cement sand (by volume) and water cement ratio of 0.5 (by weight). The cubes were made by hand compaction as the method of construction of ferro-cement only permits hand compaction.

The average compressive strength obtained by testing six mortar cubes is $3.8 \mathrm{~N} / \mathrm{mm}^{2}$.

\section{Investigation of maximum tank capacity}

The maximum tank capacity corresponding to the cases given in Table 3 were investigated.

\subsection{CASE 1 - Fully underground tank with brickwork roof, brick work wall and concrete bottom slab}

One of the objectives of the research is to investigate the possibility of using brickwork as a suitable construction material for large capacity tanks. Hence the first parametric study was carried out with respect to a normal type tank having roof and cylindrical wall out of brick masonry and a concrete base slab.

The four independent variables used to describe the geometry of a "type 1 " tank are $r_{,} l, \phi_{\sigma} r_{2}$ (see Fig.1). The capacity of the tank is decided by $r$ and $h$ as the water level inside the tank is not allowed to rise above the top of the cylindrical shell. Therefore, it was decided to maximize the value of $r$ first. However, the maximum value of $r$ that can be achieved for each part of the tank may not be the same. Hence, it was decided to 
Table 2: Flexural strength and shear strength values of brickwork

\begin{tabular}{|c|c|c|c|c|c|c|c|}
\hline \multirow[b]{2}{*}{ 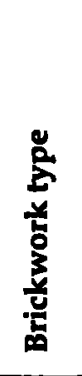 } & \multirow[b]{2}{*}{ 㟧 } & \multirow[b]{2}{*}{ 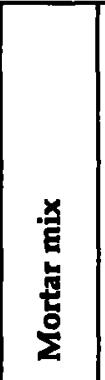 } & \multirow[b]{2}{*}{ 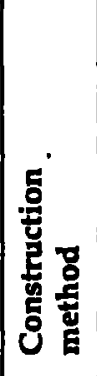 } & \multicolumn{2}{|c|}{$\begin{array}{l}\text { Flexural } \\
\text { strength } \\
\mathrm{N} / \mathrm{mm}^{2}\end{array}$} & \multicolumn{2}{|c|}{$\begin{array}{l}\text { Shear } \\
\text { strength } \\
\mathrm{N} / \mathrm{mm}^{2}\end{array}$} \\
\hline & & & & 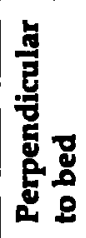 & 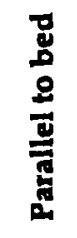 & 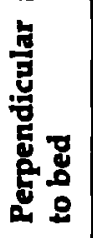 & 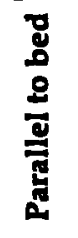 \\
\hline BT 1 & Without mesh & $1: 8$ & CM1 & 0.28 & 0.03 & 0.04 & 0.01 \\
\hline BT 2 & $\begin{array}{l}\text { No. } 2 \text { GI welded square mesh } \\
\text { (Wire dia. }=0.9 \mathrm{~mm} \text {, spacing }=12.7 \mathrm{~mm} \text { ) }\end{array}$ & $1: 8$ & $\mathrm{CM} 1$ & 0.65 & 0.30 & 0.11 & 0.07 \\
\hline BT 3 & $\begin{array}{l}\text { No. } 4 \text { GI woven square mesh } \\
\text { (Wire dia. }=0.9 \mathrm{~mm} \text {, spacing }=6.35 \mathrm{~mm} \text { ) }\end{array}$ & $1: 6$ & CM1 & 0.76 & 0.66 & 0.09 & 0.08 \\
\hline BT 4 & $\begin{array}{l}\text { No. } 6 \mathrm{Gl} \text { woven square mesh } \\
\text { (Wire dia. }=0.9 \mathrm{~mm} \text {, spacing }=4.23 \mathrm{~mm} \text { ) }\end{array}$ & $1: 6$ & $\mathrm{CM} 1$ & 0.87 & 0.70 & 0.12 & 0.09 \\
\hline BT 5 & No. 4 GI woven square mesh & $1: 6$ & CM2 & 0.85 & 0.79 & 0.10 & 0.09 \\
\hline
\end{tabular}

Note: For descriptions of $\mathrm{CM} 1$ and $\mathrm{CM} 2$ see 5.1.2

investigate the maximum value of $r$ with respect to the open spherical roof first.

The general criterion adopted to identify the maximum (or optimum) value of an input variable is that the internal stress should not exceed the design strength. The following design strengths of brickwork were used for the analysis.

Compressive strength

$$
=0.34 \mathrm{~N} / \mathrm{mm}^{2}
$$

Flexural tensile strength

Parallel to bed direction
(meridianal direction)
$=0.008 \mathrm{~N} / \mathrm{mm}^{2}$

Perpendicular to bed direction (hoop direction)

$=0.08 \mathrm{~N} / \mathrm{mm}^{2}$

Above values were obtained by applying a safety factor of 3.5 (BS 5628 : Part $1: 1992$ ) to the strength values given in Table 2.

According to the analytical results, the variation of maximum internal stresses of the spherical roof at the extreme outer fibre in the meridianal direction vs. limiting angle at top, $\phi_{y}$, is shown in Fig. 2. According to Fig. 2 the optimum value for $\phi_{0}$ is $90^{\circ}$. Then the value of the input variable $r$ was changed while keeping the value of $\phi_{0}$ as

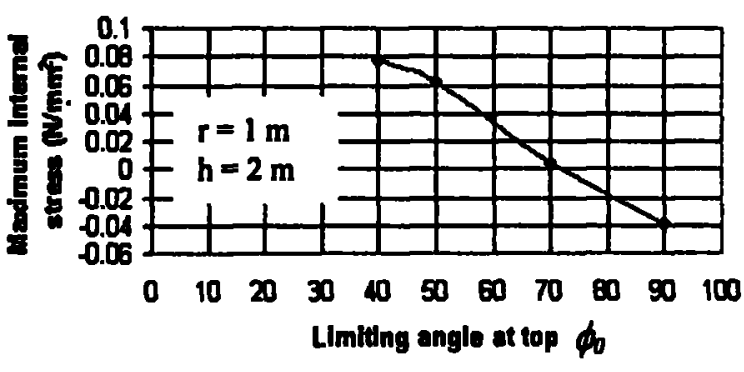

Fig. 2. Maximun internal stress variation in the spherical roof

$90^{\circ}$. The maximum internal stresses at the extreme outer fibre in the meridianal direction are the governing stresses for the spherical roof with respect to the input variable $r$ and the corresponding variation is shown in Fig. 3 .

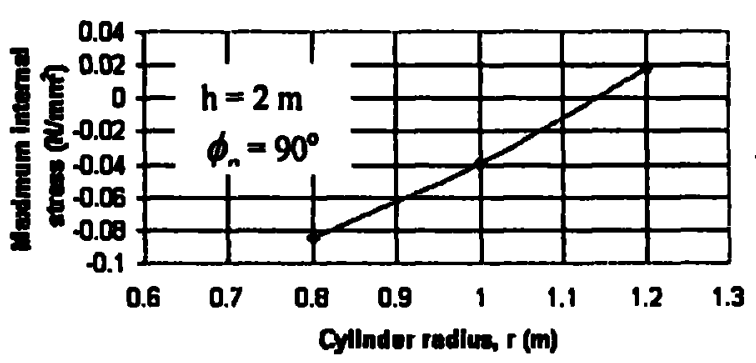

Fig. 3. Maximum stress variation in the spherical roof $w, r, t$, radius $r$.

According to Fig 3, the maximum internal tensile stress exceeds the corresponding design 
Table 3- Cases for investigating maximum tank capacity

\begin{tabular}{|c|c|c|c|c|c|}
\hline \multirow[t]{2}{*}{ Case } & \multicolumn{3}{|c|}{ Construction material } & \multirow[t]{2}{*}{ Tank position } & \multirow{2}{*}{$\begin{array}{l}\text { Tank } \\
\text { type }\end{array}$} \\
\hline & Spherical roof & Cylindrical wall & Tank bottom & & \\
\hline $\begin{array}{l}1 \\
2 \\
3\end{array}$ & $\begin{array}{l}\text { Brick work } \\
\text { Ferro-cement } \\
\text { Ferro-cement }\end{array}$ & $\begin{array}{l}\text { Brick work } \\
\text { Brick work } \\
\text { Brick work reinforced } \\
\text { with wire mesh }\end{array}$ & $\begin{array}{l}\text { Concrete } \\
\text { Ferro-cement } \\
\text { Ferro-cement }\end{array}$ & $\begin{array}{l}\text { Fully underground } \\
\text { Fully underground } \\
\text { Partially under } \\
\text { ground }\end{array}$ & $\begin{array}{l}\text { Type } 1 \\
\text { Type } 2 \\
\text { Type } 2\end{array}$ \\
\hline
\end{tabular}

strength of brickwork $\left(0.008 \mathrm{~N} / \mathrm{mm}^{2}\right)$ at approximately $\mathrm{r}=1.15 \mathrm{~m}$. Therefore, the maximum value of $\mathbf{r}$ that can be achieved by using brickwork for the spherical roof is only about $1.15 \mathrm{~m}$. With this limitation, the maximum capacity that can be achieved for the tank considered under case 1 is in the range of $10 \mathrm{~m} 3$. (The input variable $h$ cannot be increased without a limit due to the practical difficulties in construction). However, the aim is to design large capacity tanks (in the range of $60 \mathrm{~m} 3$ or more). Therefore, a ferro-cement roof was considered in the next stage of the parametric study.

6.2 CASE 2 - Fully underground tank with ferro-cement roof, brickwork wall and ferro-cement bottom

The tank considered in case 2 is a fully underground "type 2" tank. The spherical roof and the inverted spherical bottom of the tank are made out of ferro-cement and the cylindrical wall is made out of brickwork. The reasons for selecting a tank with these specifications are as follows.

1. The parametric study of case 1 revealed that the large capacity tanks could not be constructed by using brickwork for the spherical roof. Therefore, ferro-cement was considered for the spherical roof as the flexural strength of ferro-cement is higher than that of brickwork.

2. It was decided to consider an inverted spherical shell for the tank bottom. It can also be constructed with ferro-cement and it is more cost effective than the concrete bottom slab that is considered in case 1 .

3. Even though the brickwork is not a suitable construction material for the spherical roof, there had been the necessity to investigate the possibility of using brickwork for the cylindrical wall of a large capacity tank.
The five independent variables considered in the computer program for the "type 2" tanks are $r, h, \phi_{\theta} \phi_{b}$ and $r_{r}$

After identifying the optimum values for $\phi_{0}$ and $\phi_{\text {s }}$ several trial analyses were performed by changing the value of the input variable $r$, in order to determine the maximum value of $r$ with respect to the cylindrical wall.

The maximum internal stresses at the extreme inner fibre in the meridianal direction are the governing stresses for the cylindrical wall with respect to the input variable $r$ and the corresponding variation is shown in Fig. 4. According to Fig. 4, the maximum internal tensile stress exceeds the corresponding design strength of brickwork $\left(0.008 \mathrm{~N} / \mathrm{mm}^{2}\right)$ approximately at $\mathrm{r}=1.05 \mathrm{~m}$ and corresponding capacity of the tank is in the range of $10 \mathrm{m3}$. Therefore, the limiting factor which decides the maximum capacity of the tank is the flexural strength of brickwork. Hence it was decided to reinforce the brickwork with wire mesh in order to increase the flexural strength of brickwork. This option was considered in the next stage of the parametric study.

\subsection{CASE 3 - Partially underground tank}

The tank considered in case 3 was a partially underground "type 2" tank. The spherical roof and the inverted spherical bottom of the tank are made out of ferro-cement and the cylindrical wall is made out of brickwork reinforced with wire mesh (BRWM).The reasons for selecting a tank with these specifications are as follows.

With the knowledge gained from the parametric studies for case 1 and case 2, it was understood that the large capacity tanks could not be constructed by using normal brickwork because of the low flexural strength of brickwork. Therefore, it was decided to use brickwork reinforced with wire mesh for the cylindrical wall. 
To reduce the imposed load on roof, it was decided to keep the spherical roof above the ground surface and that gives a partially underground tank.

The design strength values used for Case 3 are as follows:

For brickwork reinforced with wire mesh (BRWM),

Compressive strength

$$
=0.34 \mathrm{~N} / \mathrm{mm}^{2}
$$

Flexural tensile strength Parallel

$$
\text { to bed (meridianal direction) }
$$$$
=0.22 \mathrm{~N} / \mathrm{mm}^{2}
$$

Perpendicular to bed (hoop direction)

$$
=0.24 \mathrm{~N} / \mathrm{mm}^{2}
$$

For ferro-cement.

$$
\begin{aligned}
& \text { Compressive strength } \\
& =1.9 \mathrm{~N} / \mathrm{mm}^{2}
\end{aligned}
$$

Flexural tensile strength

$=0.5 \mathrm{~N} / \mathrm{mm}^{2}$

Above values were obtained by applying a safety factor of 3.5 (BS 5628 : Part $1: 1992$ ) to the strength values of BRWM and a safety factor of 2.0 for ferro-cement (Kumar, 1992).

The five input variables considered in the computer programme for the advanced type are $r, h, \phi_{0}, \phi_{b}$ and $r_{1}$.

After optimising the $\phi_{\sigma}$ and $\phi_{\nu}$ several trial analyses were performed by changing the value of the input variable $r$ in order to determine the maximum value of $r$.

The governing stress condition for the spherical roof with respect to input variable $r$ is the maximum internal stress in the hoop direction (the stress at both extreme inner and extreme outer fibres are the same). Corresponding variation is shown in Fig.5. According to Fig. 5, the maximum internal tensile stress exceeds the design strength (i.e. $0.5 \mathrm{~N} / \mathrm{mm}^{2}$ ) when $r$ is approximately $3.75 \mathrm{~m}$.

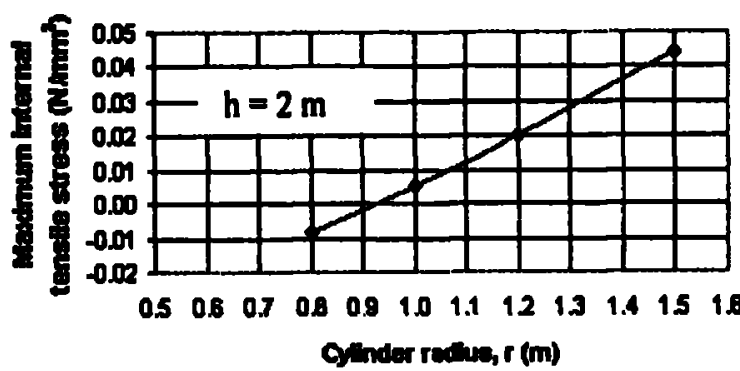

Fig. 4 Variation of maximum stress in the cylindrical wall

The governing stress condition for the cylindrical wall is the maximum internal stresses at the extreme outer fibre in the hoop direction. Corresponding variation is presented in Fig. 6. According to that, when $r=3.75 \mathrm{~m}$, maximum internal stress is $0.22 \mathrm{~N} / \mathrm{mm}^{2}$ and it is less than the design strength in the perpendicular to bed direction for the BRWM (i.e. $0.24 \mathrm{~N} / \mathrm{mm}^{2}$ ).

The governing stress condition for the inverted spherical bottom is the minimum internal stress at the extreme outer fibre in the meridianal direction. Corresponding variation is presented in Fig. 7. According to the variation, when $r=$ $3.75 \mathrm{~m}$, maximum internal compressive stress is $1.55 \mathrm{~N} / \mathrm{mm}^{2}$ and it is less than the design compressive strength of ferro-cement (i.e. $1.9 \mathrm{~N}$ / $\mathrm{mm}^{2}$ ).

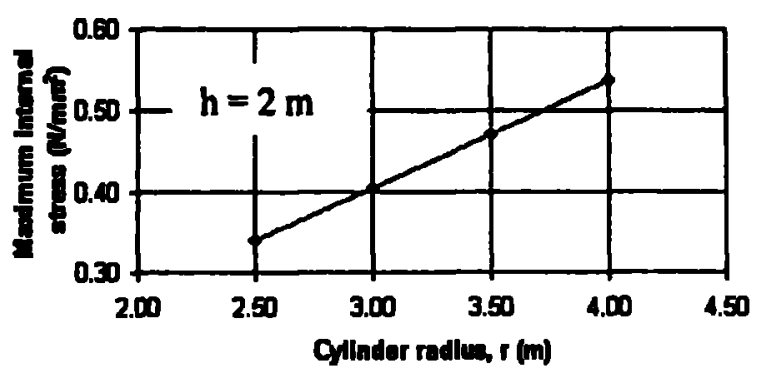

Fig. 5. Variation of Maximum intemal stress in the spherical noof

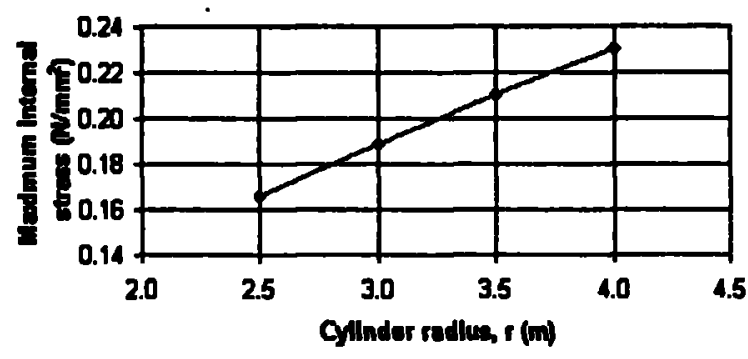

Fig. 6. Variation of Maximum internal stress in Cylinder radius 
Therefore, it can be concluded that the maximum value of input variable $r$ is about 3.75 $m$ with respect to all parts of the tank (i.e. roof, wall and the bottom) and it is governed by the maximum internal stress in the hoop direction of the spherical roof. However, the value of 3.75 $\mathrm{m}$ is obtained by considering a cylinder height of $2 \mathrm{~m}$ and the maximum value of $\mathrm{r}$ will vary depending on the height of the cylinder. Therefore, trial analyses were performed by changing the value of the input variable $h$ while keeping cylinder radius $\mathrm{r}$ as $3.5 \mathrm{~m}$. Internal stresses occurring in the spherical roof, cylindrical wall and the inverted spherical bottom were recorded.

The governing stress condition for the cylindrical wall is the maximum internal stress at the extreme outer fibre in the hoop direction. Corresponding variation is presented in Fig. 8. According to Fig.8, the maximum internal stress exceeds the design strength of BRWM (i.e. 0.24 $\mathrm{N} / \mathrm{mm}^{2}$ ) at approximately $\mathrm{h}=2.25 \mathrm{~m}$.

The governing stress condition for the inverted spherical bottom is the minimum internal stresses at the extreme outer fibre in the meridianal direction. Corresponding variation is

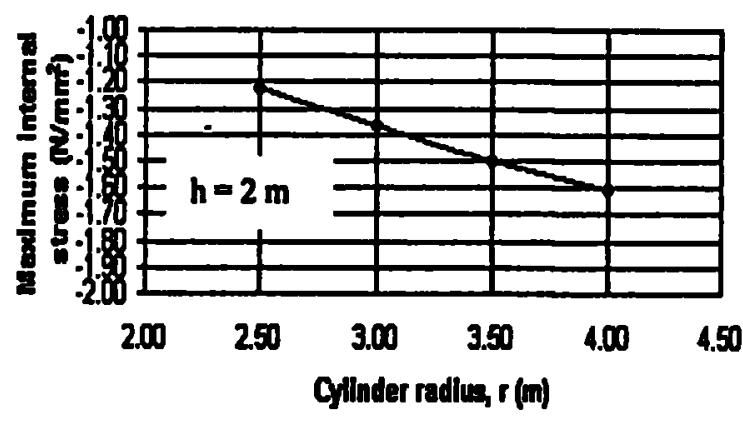

Fig. 7. Variation of Maximum internal stress in the inverted spherical bottom presented in Fig. 9. According to the variation, when $\mathrm{h}=.2 .25 \mathrm{~m}$ maximum internal compressive stress is $1.7 \mathrm{~N} / \mathrm{mm}^{2}$ and it is less than the design compressive strength of ferrocement (i.e. $1.9 \mathrm{~N} / \mathrm{mm}^{2}$ ).

Therefore, it can be concluded that the maximum value of input variable $h$ is about 2.25 $m$ with respect to all parts of the tank (i.e. roof, wall and the bottom) and it is governed by the maximum internal stresses at the extreme outer fibre in the hoop direction of the cylindrical wall. However, the maximum cylinder height of $2.25 \mathrm{~m}$ is obtained by considering a cylinder radius of $3.5 \mathrm{~m}$ and the maximum value of $h$ will vary depending on the radius of the cylinder.

The maximum value of the tank capacity that can be achieved with the maximum dimensions determined for case 3 is about $100 \mathrm{~m}^{3}$. This is a notable achievement compared to case 1 and case 2. However, these maximum dimensions may vary slightly depending on the loading and the ground conditions. Hence a structural design was carried out for a partially underground tank having a ferro-cement spherical roof, BRWM cylindrical wall and a ferro-cement inverted spherical bottom. Fig. 10 shows a structural

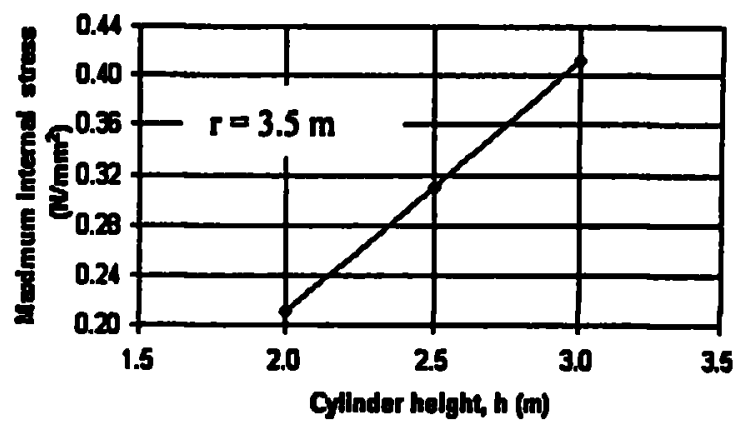

Fig. 8. Variation of Maximum internal stress in cylindrical wall

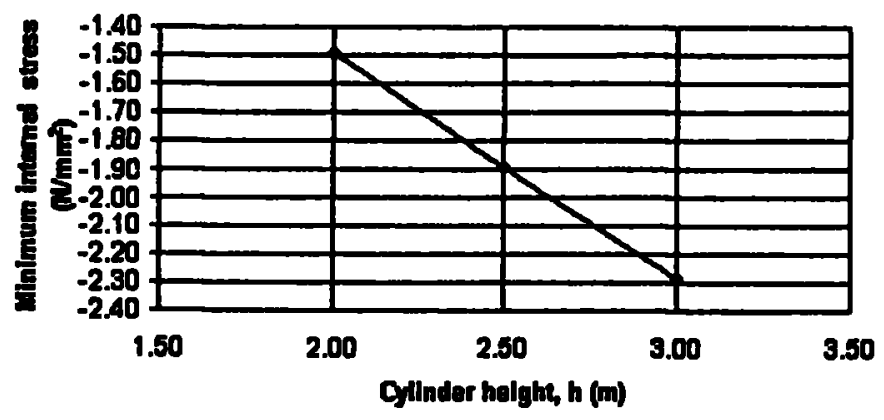

Fig. 9. Variation of Maximum internal stress in the inverted spherical bottom 


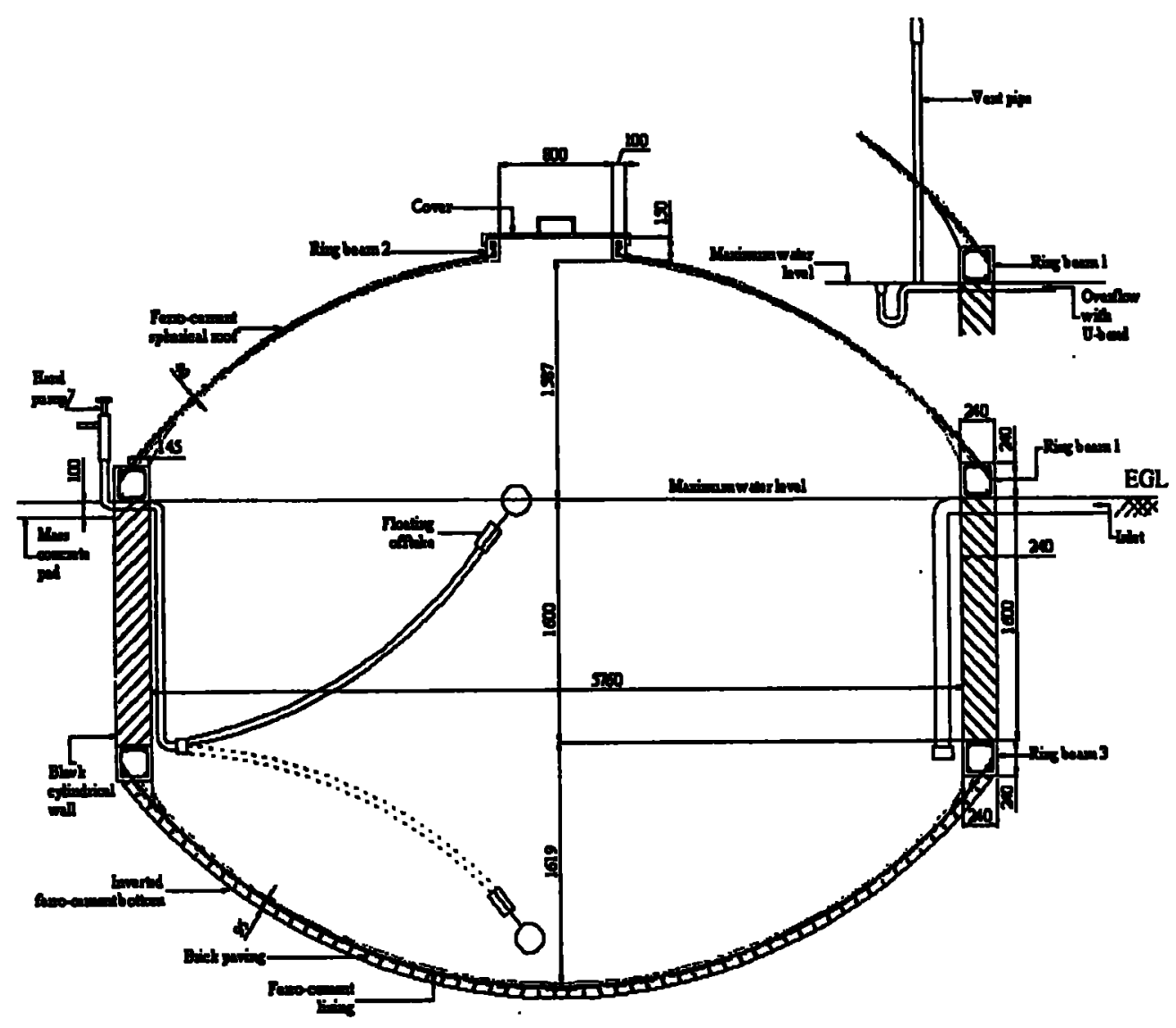

Fig. 10. Structural drawing of the composite tank of capacity $66 \mathrm{~m}^{3}$

drawing of the partially underground "type 2" tank of capacity $66 \mathrm{~m}^{3}$.

The following recommendations can be made based on the detailed design of the $66 \mathrm{~m}^{3}$ capacity tank.

- If it is possible to ensure that the tank is subjected to an adequate earth confinement at all times, the cylindrical wall can be constructed with No. 4 woven mesh fixed to the entire inner surface only. This permits excavation merely against the outer surface of the cylindrical wall without leaving additional working space in order to fix the outer mesh.

- If it is not possible to ensure that the tank is subjected to an adequate earth confinement at all times, it is recommended to have No. 2 welded mesh on the entire outer surface in addition to the No. 4 woven inner mesh. However, a higher factor of safety can be achieved against a possible failure by having No. 4 woven mesh for both inner and outer surfaces.
- The entire cylindrical wall can be constructed above the ground surface leaving only the inverted spherical bottom below the ground surface. For this option, it is necessary to have an outer mesh layer of No. 2 welded mesh in addition to the inner No. 4 woven mesh. With this option, the excavation cost can be greatly reduced and it results in easy construction of the cylindrical wall even with the outer mesh. With this option, it is possible to eliminate most of the problems associated with the underground water tanks such as problems due to root penetration, difficulty to detect and rectify water leakages, etc.

\section{Concluding Remarks}

The study was basically carried out to explore the avenues of having low cost underground water tanks with large capacities using locally available low cost construction materials.

The results of the parametric study revealed that the maximum capacity that can be achieved by using normal brick masonry for the roof and the 
cylindrical wall of the tank is only about $10 \mathrm{~m}^{3}$. The main reason for this limitation is the very low flexural strength of normal brickwork.

The results of the experimental investigations indicated that the flexural strength could be increased significantly by reinforcing the brickwork with wire mesh. According to the results, the flexural strength of brickwork reinforced with No. 4 woven mesh, in parallel to bed direction is twenty six times higher than that of normal brickwork. These research findings resulted in a new composite construction material, which is named as Brickwork Reinforced with Wire Mesh (BRWM).

The experimental investigations revealed that the flexural strength of ferro- cement is slightly higher than that of brickwork reinforced with wire mesh (BRWM). However, BRWM is more suitable for the cylindrical wall than the ferrocement due to the following reasons:

- For ferro-cement to be used for the cylindrical wall, the ground should be firm in order to attain the required shape.

- The brick work layer of the BRWM serves as a firm formwork for the reinforcing mesh, eliminating the requirement of the ground to be firm.

The parametric study was performed for a partially underground tank having a ferrocement spherical roof, ferro-cement inverted spherical bottom and a BRWM cylindrical wall. The results of the study revealed that the maximum capacity that can be achieved is about $100 \mathrm{~m}^{3}$, which is a notable achievement compared to the capacity of $10 \mathrm{~m}^{3}$ with the normal brickwork.

The possibility of constructing the entire cylindrical wall above the ground surface leaving only the inverted spherical bottom below the ground surface was also investigated. With this option, it is necessary to have an outer mesh layer to strengthen the brickwork. However, with this option the excavation cost can be greatly reduced and it results in easy construction of the cylindrical wall even with the outer mesh. Also, most of the problems associated with the underground water tanks such as problems due to root penetration, difficulty to detect and rectify water leakages, etc. can be eliminated with this option.
Finally, it should be noted that even though the design can be confirmed by incorporating the complex structural analysis and design methodologies, it is critically important to have some feed back from actual construction and operational experience in order to refine and standardise the design.

\section{Acknowledgements}

The authors would like to acknowledge the assistance given by the National Water Supply and Drainage Board by proving necessary funding for the research. The technical assistance received from $\mathrm{Mr}$. T. Nanthanan is also gratefully acknowledged.

\section{References}

(1) ACl 549.1R, Guide for design, Construction, \& Repair of Ferrocement, American concrete Institute, 1993

(2) Baker, E. H., Kovalevsky, L and Rish, F. L. "Structural analysis of shells" United States of America: Halliday Lithograph Corporation, 1972.

(3) BS 5268: Part 1: 1992, Use of Masonry: Structural use of Unreinforced Masonry, British Standards Institution.

(4) Herath, Neil. "Construçtion of wire-reinforced cement mortar tanks." Community Water Supply and Sanitation Project (CWSSP), Sethsiripaya, Battaramulla, 1995.

(5) Kumar , Kunnath Sashi. "FC TANK : An interactive Microcomputer Program for the Analysis and Design of Ferrocement Storage Tanks." Asian institute of technology, Bangkok, Thailand : International Ferrocement Information Center, May 1992.

(6) Kumara, G.C.P, Kumara, G.A.A.C, Nishantha, S.H.C.V., Senadhira, G,J,L.,. "Mechanical and material properties of ferro-cement and design of $80 \mathrm{~m}^{3}$ water storage tank". Final year project report, Department of Civil Engineering, University of Peradeniya, Sri Lanka, 1999.

(7) Ranjendram, I. "Some Aspects in the Analysis of 'Intze' Type Water Tanks." Transactions of the Institute of Engineers, Ceylon, pp 53-80.

(8) Rees, Dai. "Partially Below Ground Tank for Rainwater Storage." DTU Technical release TRRWH 01 ; Development technology unit (DTU), Department of Engineering, University of Warwick, November 2000. 
(9) SLS 39 : 1978 - Specification for Common Burnt Clay Building Bricks, Sri Lanka Standards Institution. (First revision).

(10) Thomas, Terry and McGeever, Ben. "Underground Storage of Rain Water for Domestic Use." Working paper No. 49 : Development Technology Unit (DTU), Department of Engineering, University of Warwick, July 1997.

(11) Vadhanavikkit, Chayatit and Viwathanathepa, Suthipol. " $12 \mathrm{~m}^{3} / 14.5 \mathrm{~m}^{3}$ Brick Water tank, Thailand." Research paper, Khon kaen University, Thailand, 1983. 